Having obtained $\mathrm{C}$, we put the instrument in the direcence of the same center $o$. 16. If the distance of the points $A$ and $B$ were ton great then it would be easy to determine a series of points belong-
ing to the arc of circumference sought (Fig. 4 . I lay off $\mathrm{C} E=d$, draw $A \mathrm{E} B$ perpendicularly, and calcu-

$$
d=(\mathrm{R}-d)=\overline{\mathrm{AE}^{2}} ;
$$

or, as absolute value, $\mathrm{A} \mathrm{E}=\sqrt{d(\mathrm{R}-d)}$.

(10)

The instrument being arranged according to $\mathrm{A} C \mathrm{C}$, I pro-
long $\mathrm{C} B$ and take $\mathrm{B} \mathrm{C}^{\prime}=\mathrm{B}$, when $\mathrm{C}^{\prime}$ will be one of the points sought. It will be readily understood bow, by repeat-

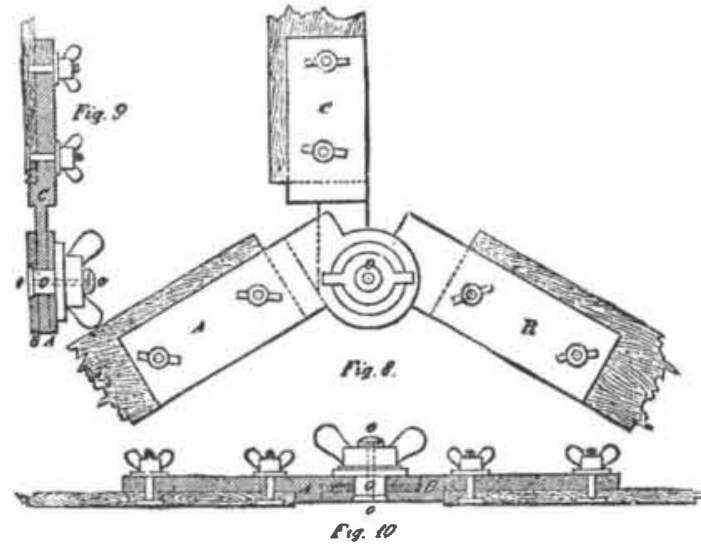

obtain the other intermediate points, and how we may con

out. If the three rulers were three arcs of a large circle of
17. a spbere, the instrument might serve for drawing the meridians on such spher

18. If we imagine, instead of three axes placed in one plane and converging at one point, a system of four axes also conin space, and if we rest three of them against three fixed gous to those that have just been solved in a plane. If we bad, for example, to draw a spherical vauli. whose center Génie Civil.

FEED-WATER HEATER AND PURIFIER.* By George S. Strong.

In order to properly understand the requirements of an effective feed-waterpurifier, it will be necessary to understand something of the character of the impurities of natural waters
used for feeding boilers, and of the manner in which they become troublesome in causing incrustation or scale, as it is commonly called, in steam boilers. All natural waters are in solution and partly in mechanical snspension. These minearth's surface, and by percolation through its soil and rocks. The substances taken up in solution by this process magnesia, and the chloride of sodium. The materials carmatter. There are many other saline ingredients in various
natural waters, but they exist in such minute quantities, and natural waters, but they exist in such minute quantities, and
are generally so very soluble, that their presence may safely be ignored in treating of the utility of boiler waters. Of the above named salts, the carbonates of lime and marbonic acid
Our American rivers contain from 2 to 6 grains of saline mater to the gallon in solution, and a varying quantity-
generally exceeding 10 grains to the gallon-in mechanical generally exceeding 10 grains to the gallon-in mechanical suspension. The waters of wells and springs bold a smaller
quintily in suspension, but generally carry a larger percentgrains to the gallon.

When waters containing the carbonates of lime and magnesia in solution are boiled, the carbonic acid is driven off, and the salts. deprived of their solvent, are rapidlv precipi-
tated in fine crystalline particles, which adhere tenaciously to wbatever surface they fall upon. With respect to the sulphate of lime, the case is different. It is at best only requiring nearly 500 parts of water to dissolve it. As the requiring nearly 500 parts of water to dissolve it. As the
water evaporates in the boiler, however, a point is soon
reached where supersaturation occurs, as the water freshly reached where supersaturation occurs, as the water freshly
fed into it constantly brings fresh accessions of the salt; and when this point is reached, the sulphate of lime is pre-
cipitated in the same form and with the same tenaciously adverent quality as the carbonates. There is, however, peculiar property possessed by this salt which facilitates its since, if - properly taken advantage of, it is possible to effect its almost complete removal from the feed-water of boilers,
There is little difference in the solubility of the sulphate There is little difference in the solubility of the sulphate
of lime until the temperature has risen somewhat above $300^{\circ}$, all of this salt, beld in solution at lower temperatures, will be precipitated when the temperature has risen to that point. The following tablet represents the solubility
sulphate of lime in sea water at different temperatures:

* A paper read before the Franklin Institute.

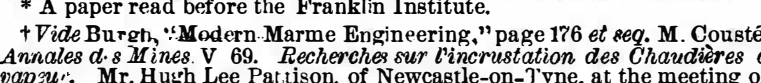

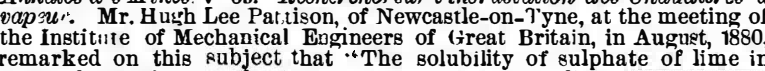

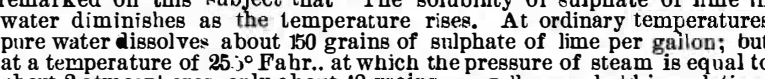

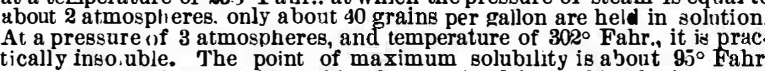

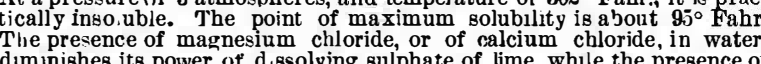

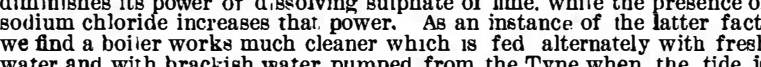
we find a boiler works much cleaner which is fed alternately with fresh
water and with brackish water pumped from the Tyne when the tide is
bigh than one which is fed with fresh water constantly."

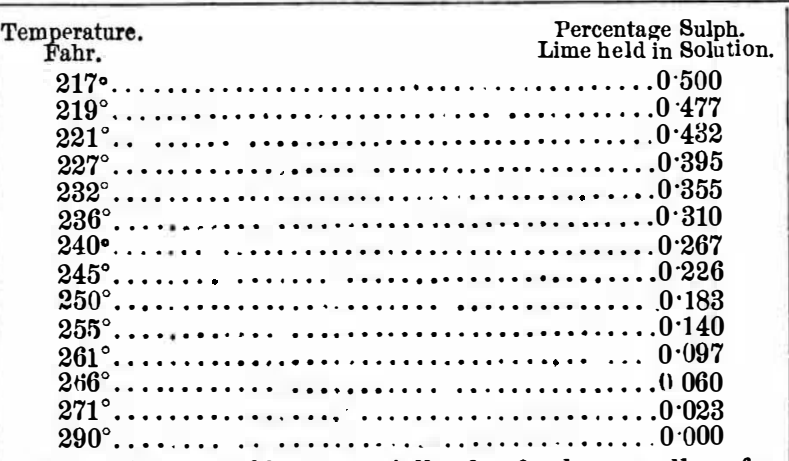

These figures bold substantially for fresh as well as for ble in sea water, or in soft water, at temperatures comprised between $280^{\circ}$ and $300^{\circ}$ Fabr.
It appears from this that it is simply necessary to beat water up to a temperature of $250^{\circ}$ in order lo effect the precipitation of four tifths of the sulphate of lime it may bave
contained, or to the temperature of $290^{\circ}$ in order to precipi. contained, or to the temperature of $290^{\circ}$ in order to precipi-
tate it entirely. The bearing of these facts on the purificaoffered to account for the gradually increasing insolubility offer to account for the gradually increasing insolubility
of sulphate of lime on heating, is, that the hydrate, in
which which condition it exists in solution, is partially decom.
posed, anhydrous calcic sulpbate being formed, ihe dehydration becoming more and more complete as the temperature rises. Sulphate of magnesia, chloride of sodium (com-
mon salt), and all the other more soluble salts contained in natural waters are likewise precipitated by the process of supersaturation, but owing to their extreme solubility their
precipitation will never be effected in boilers: all mechan icallv suspended matter tends naturally to subside.

Where water containing such mineral and suspended matof which the carbonate of pime usually forms the greate part, and which remains more or less firmly adherent to the part, and which remains more or less brmly anherent to the boiling currents. Gradually accumulating, it becomes
harder and thicker, and, if permitted to accumulate, may at nth attain such thickuess as to prevent the proper heat g of the water by any fire that may be maintained in the
urnace. Dr. Joseph G. Rogers, who bas made boiler waters and incrustations a subject of careful study, declares scale will sometimes actually convert the scale into a species of glass, by combining the sand, mechanically separated,
with the alkaline salts. The same authority bas carefully with the alkaline salts. The same authority has carefully
estimated the non-conducting properties of such boiler inestimated the non-conducting properties of such boiler in-
crustations. On this point he remarks that the evil effects of the scale are due to the fact that it is relatively a nonconductor of heat. As compared with jron, its conducting
power is as 1 to $37 \frac{1}{2}$, consequently more fuel is required to heat water in an incrusted boiler than in the same boiler if clean. Rogers estimates that a scale $1-16$ th of an inch thick
will require the extra expenditure of 15 per cent. more fuel, and this ratio increases as the scale grows thicker. Thus,
when it is one-quarter of an incb thick, 60 per cent. more when it is one-quarter of an incb tlick, 60 per cent. more
fuel is needed; one-half inch, 112 per cent. more fuel, and on.
Rogers very forcibly shows the evil consequences to the Rogers very forcibly shows the evil consequences to the
oilerf rom the excessive heating required to raise steam in
badly incrusted boiler, by the following illustration: To badly incrusted boiler, by the following illustration: To
ise steam to a pressure of 90 pounds the water must be raise steam to a pressure of 90 pounds the water must be
heated to ahout $3: 0^{\circ} \mathrm{Fahr}$. In a clean boiler of one-quarter nch iron this may be done by heating the external surface
of the shell to about $325^{\circ} \mathrm{Fahr}$. If, now, one-balf an inch $f$ scale intervenes between the boiler shell and the water, sucb is its quality of resisting the passage of beat that it will be necessary to heat the fire surface to about $700^{\circ}$,
almost to a low red heat, to effect the same result. Now, the higher the temperature at which iron is kept the more rapidly it oxidizes, and at any heat above $600^{\circ}$ it very soo or otherwise give way to the internal pressure. This condition predisposes the boiler to explosion and makes expensive
repairs necessary. The presence of such scale, also, renders more difficult the raising, maintaining, and lowering of The nature of incrustation and the evirs resulting therefrom having been stated it now remains to consider the methods naturally resolve themselves into two kinds, chemical and mechanical. The chemical method has two modifi-
cations; in one the design is to purify the water in large tanks or reservoirs, by the addition of certain substance which shall precipitate all the scale-forming ingredients be-
fore the water is fed into the boiler; in the otber the chemical agent is fed into the boiler from time to time, and the
object is to effect the precipitation of the saline matter in such a manner that it will not form solid masses of adherent scale. Where chemical methods of purification are resorted to, the latter plan is generally followed as being the
least troublesome. Of the many substances used for this purpose, however, some are measurably successful; the ma-
jority of them are unsatisfactory or objectionable. The mechanical methods are also very various. Picking she scale is so tenacious that this only partially succeeds,
and, as it necessitates stoppage of work, it is wasteful. In ddition to this plan, a great variety of mechanical con rivances for heating and purifying the feed-water, by sepa-
rating and intercepting the saline matter on its passage are of great utility and have come into very general use. In the Western States especially, where the water in mos localities is heavily cbarged with lime, these mechanical users are alive to the necessity of generating steam wit Most of these appliances, however, only partly fulfill their
ntended purposes. They consist. essentially of a chamber hrough whicb the feed-water is passed, and in which it is heated almost to the boiling point by exhaust steam from the engine. According to the temperature to whicb the
water is heated in this chanber, and the length of time rewater is heated in this chanber, and the length of time re-
quired for its passage througli the chamber, the carbonates quired for its passage througl the chamber, the carbonate matter beld in mecbanical suspension. The precipitate which it is removed from time to time. The sulphate of cases also a portion of the carbonates that were not precipitated during the brief time of passage through the heater,
are passed on into the boiler.
Appreciating this insufficiency of existing feed-water
purifiers to effiectually remove these dangerous saline im. purities, the writer in designing the feed-water beater now
to be described paid specialattention to the separation of all matters, soluble and insoluble, and he has succeeded in pass
iug the water to the boilers quite free from any substance ing the water to the boilers quite free from any substance
which would cause scaling or coberent deposit. His attention was called more particularly to the necessity of extreme cure in heavily charged with lime. Very simple and even primitive boilers are here used: the most necessary considerition being bandiness in cleaning, and not the bighest evaporative
efficiency. These boilers are therefore very wasteful, only evaporating, when covered with lime scale, from two to
three pounds of water with one pound of the best coal, and three pounds of water with one pound of the best coal, and
requiring cleansing once a week a the very least. The to remedy these inconveniences, and accordingly be made a careful study of the subject, and examined all the beaters
then in the market. He found them all, without exception, then in the market. He found them all, without exception, usufficient to free the feed-water from the most dangerous
of impurities, namely, the sulphate and the carbonate of Taking the foregoing facts, well known to chemists and ngineers, as the basis of his operations, the writer perceived that all substances likely to give trouble by deposition
would be precipitated at a temperature of about $250^{\circ} \mathrm{F}$. vould be precipitated at a temperature of about $250^{\circ} \mathrm{F}$.
His plan was, therefore, to make a feed-water heater in wich the water could be raised to that temperature before atering the boiler. Now, by using the heat from the ex

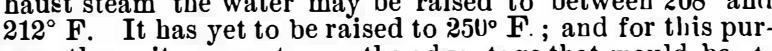
pose the writer saw at once the advantage that would be attained by using a coil of live steam from the boiler. This
device does not cause any loss of steam, except the small device does not cause any loss of steam, except the small
loss due to radiation, since the water in any case would have loss due to radiation, since the water in any case would have
to be beated up to the tem perature of the steam on entering Be boiler. By adopting tbis metbod, the chemical precipi-
tion which would otherwise occur in the boiler, takes place in the beater; and it is only necessary now to provide
fiter, which shall prevent anything passing that can possifilter, which shall prevent anything passing that can possi-
bly cause scale. Having explained as briefly as possible the principles on
which the svstem is founded, the writer will now describe which the sustem is ounded,

In Figs. 1 and 2 are shown an elevation and a vertical sec-
Inter

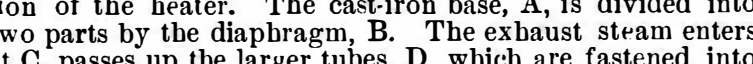
the passes up the laryer tubes, D, wbich are fastened into , which are inside the others, and passes away by the

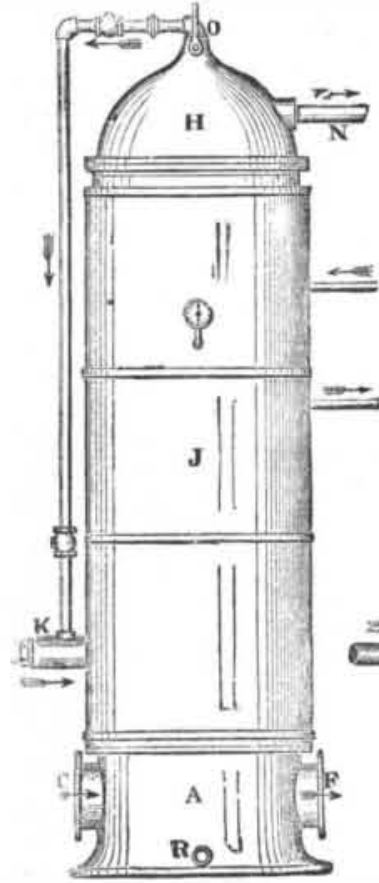

Frg. 1.-Elevation.

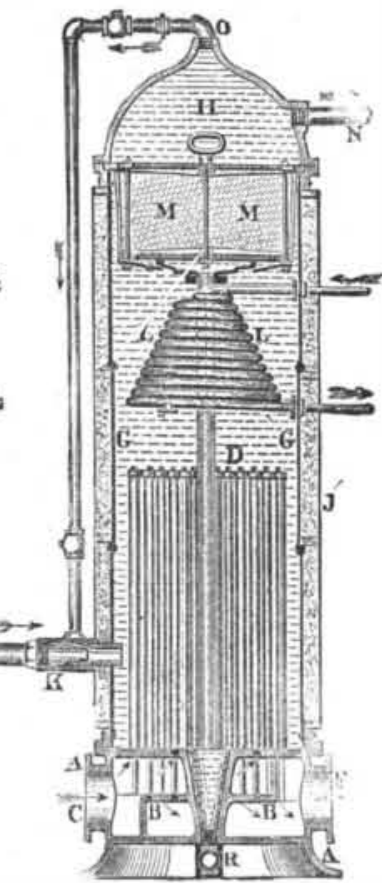

Frg. 2.-Vertical Section will be seen at once that this arrangement, while securing great heating surface in a small space, at the same time
leaves freedom for expansion and contraction. without producing strains. The free area for passage of steam is ar o that there is no possible danger of back pressure. The wrought iron shell, $G$, connecting the stand, $A$, with the
dome, $H$, is made strong enough to withstand the full boiler dome, $H$, is made strong enough to withstand the full boiler
pressure. An ordinary casing, $J$, of wood or otber malerial he pump passes into the heater through the injector arrangement, $K$, and coming in contact with the tubes, $D$, is
heated; it then rises to the coil, $L$. which is supplied with
steam from the boiler. and thus becomes further heated steam from the boiler. and thus becomes further heated attaining there a tell perature of from $250^{\circ}$ to $270^{\circ} \mathrm{F}$, accord-
ing to the pressure in the boiler. This high temperature causes the separation of the dissolved salts; and on the way
to the boiler the water passes through the filter, $M$, becom ing thereby freed from all precipit ated matter before passing away to the boiler at $N$. The purpose of the injector, $K$, and the pipe passing from $O$ to $K$, is to cause a continua
passage of air or steam from the upper part of the dome to be lower part of the heater, so that any precipitate carrie up in froth may be again rel urned to the under side of the
filter, in order more effectually to separate it, before any The filter consists of wood cbarcoal in the lower half an
chance occurs of its pasing into the boiler. bone black above firmly held between two perforated plates, as shown. After the heater has been in use for from
bree to ten hours, according to the nature of the water used. it is necessary to blow out the beater, in order to clea and the water is discharged by the pressure from $\mathrm{R}$ opened, The steam is allowed to pass through the heater for som little time, in order to clear the filter completely. After this operation, all is ready to commence work again. By change of the charcoal. 


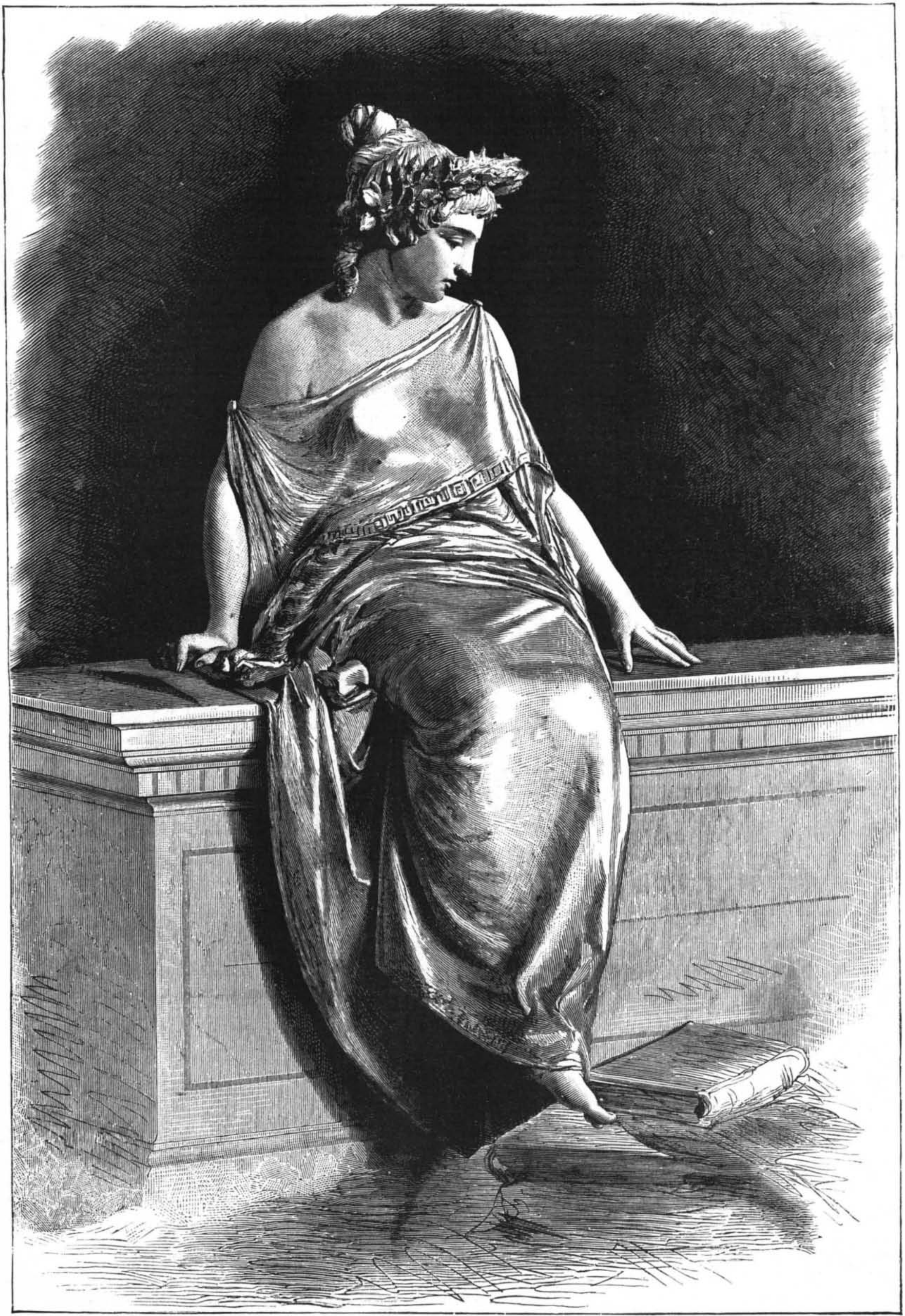

LA ARCHITECTURA.-STATUE BY JULI MONTEVERDE MRECTED IN MEMORY OF THE ARCHTTECT, G:ARLFS SADA 
\begin{tabular}{l|l|l|l|} 
Where a jet condenser is used, either of two plans may be & There are hatchways in the attic floor, which open upon & particles that lodge in the throat of the visitor, and by the \\
adopted. One plan takes the feed-water from the hot well & rotary iron boilers. Into these boilers the chips are raked, & frequent coughing of the sorters. They protect their hair
\end{tabular} adopted. One plan takes the feed-water from the hot well rotary iron boilers. Into these boilers the chips are raked, frequent coughing of the sorters. They protect their hai heater, using at the same time an increased amount of coil for the live steam. By this means a temperature of water is and after cooking tive hours the chips are reduced to a ance of an industrious Turkish harem. Short, sharp scythe attained high enough to cause deposition, and at the same mass of soft black pulp. Each rotary will contain two blades, like Turkish scimeters, gleam above all the girls time to produce decomposition of the oil brougbt over from cords of chips. After the cooking, the pulp is dumped into benches. When a sorter wishes to cut a rag. she pulls it the cylinders. The other plan places the heater in the line of exhaust from the engine to the condenser, also using a
larger amount of coil. Both these methods work well. The writer sometimes uses the steam from the coil to work tbe feed pump; or, if the heater stands high enough, it is only necessary to make a connection with the boiler, when back to the boiler, and thus the coil is kept constantly at the necessary temperature.
In adapting the heater to locomotives, we were met with the difficulty of want of space to put a beater sufficiently large to bandle the extremely large amount of water evaporated on a locomotive worked up to its full capacity, being
from 1,500 to 2,500 gallons per hour, or from five hundred to one thousand $h$. p. We designed various forms of heaters in the engraving, Fig. 3, which consists of a lap welded iron head which is divided into two compartments or chambers by a diaph ragm. Into this head are screwed 60 tubes, one inch outside diameter and 12 feet long, which are of seam-
less brass. These are the heating tubes, within which are internal tubes for circulation only, which are screwed into the diaphragm and extend to within a very short distance of
the end of the heating tube. The exhaust steam for heating is taken equally from both sides of the locomotive by interfering with the free escepe of the steam for the blast, and without any back pressure, as it relieves the back
pressure as much as it condenses. The pipe from one side pressure as much as it condenses. The pipe from one side
of tbe engine is connected with the chamber into which the heating tubes are screwed, and is in direct communication the chamber into which the circulating tubes are screwed. The beat of the exhaust, working, as it does, on the quarters, causes a constant sawing or backward and forward circulation of steam without any discharge, and only the condensa-

The water is brought from the pump and discharged into
the lower side of the heater well forward, and passes around the lower side of the heater well forward, and passes around
the heating tubes to the end, when it is discharged into a pipe that carries it forward, either direct to the cbeck or into the purifier, which is located between the frames under the boiler, and consists of a chamber in which are arranged a
live steam coil and a filter alove the coil. The water coming in contact with the coil, its temperature is increased from the temperature of the exhaust, $210^{\circ}$, to about $250^{\circ}$ Fahr. which causes the separation of the lime salts as before dethe boilerf rom above the filter, which is cleansed by blowing back through it as before described.

One of these heaters lately tested showed a saving in coal of 22 per cent. and an increase of evaporation of $1 \cdot 0$
pounds of water per pound of coal. - Franktin Journal.

\section{MONTEVERDE'S STATUE OF ARCHITECTURE.}

THrs precious statue forms the noble figure that adorns the monument erected to the memory of the architect monument is 20 feet high, the superior portion consisting of a sarcophagus resting upon a level base. Upon this sarlana. n tanks in the basement, where it is thoroughly washed across the edge of this blade, and is not obliged to bunt for
ith streams of clean cold water. It is then pumped into a pair of shears. a machine which rolls it into broad sheets. These sheets are a pair of shears. olded, and condensed by a hydraulic press of 200 tons pres. pockets, concaining small sums of money, are occasionally
sure. This process reduces its bulk fifty per cent., and sends
found. A foreign coin valued at about $\$ 3$ was found a few profuse jets of water flyiug out of it. The soda ash, in days ago. In the paper stock, quaint and valuable old books

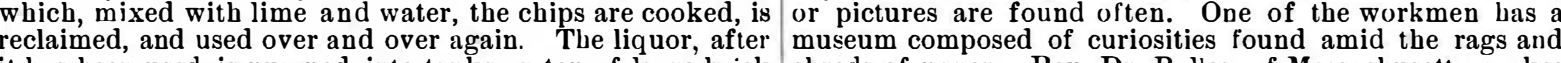
it bas been used, is pumped into tanks on top of large brick shreds of paper. Rev. Dr. Bolles, of Massachusetts, makes
furnaces. As it is heated it thickens. It is brought nearer and nearer the fire until it crystallizes, and finilly burns into rare old pamphlets, books, and engravings that he mav dig an ash. Eighty per cent. of the ash used is thus reclaimed. out This process is an immense saving to the pulp manufac- Stuffed in hogsheads, the rags are lowered from this room turers. The work in the pulp mill is severe, and is slightly through a batchway, and are given a red hot lime batb. They

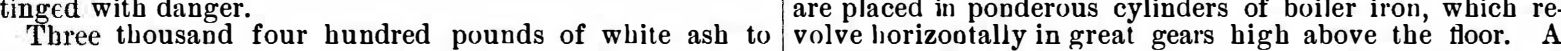

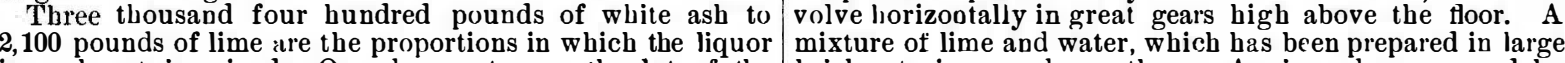
in each vat is mixed. One does not envy the lot of the the chips. The hurry of business is so great that they can. around, and churns the rags in the lime-juice twelve hours. not wait for these boilers to cool naturally, after they have This process is called bleaching. When the rags come out

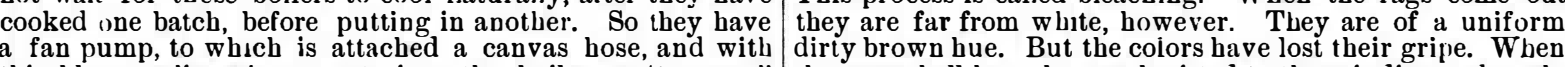
this blow cooling air currents into the boiler, or "rotary," the rags shall have been submitted to the grinding and wash.
us they call it. The rotary is subjected to an immense pres- ing in pure water, as we shall see them presently, they are

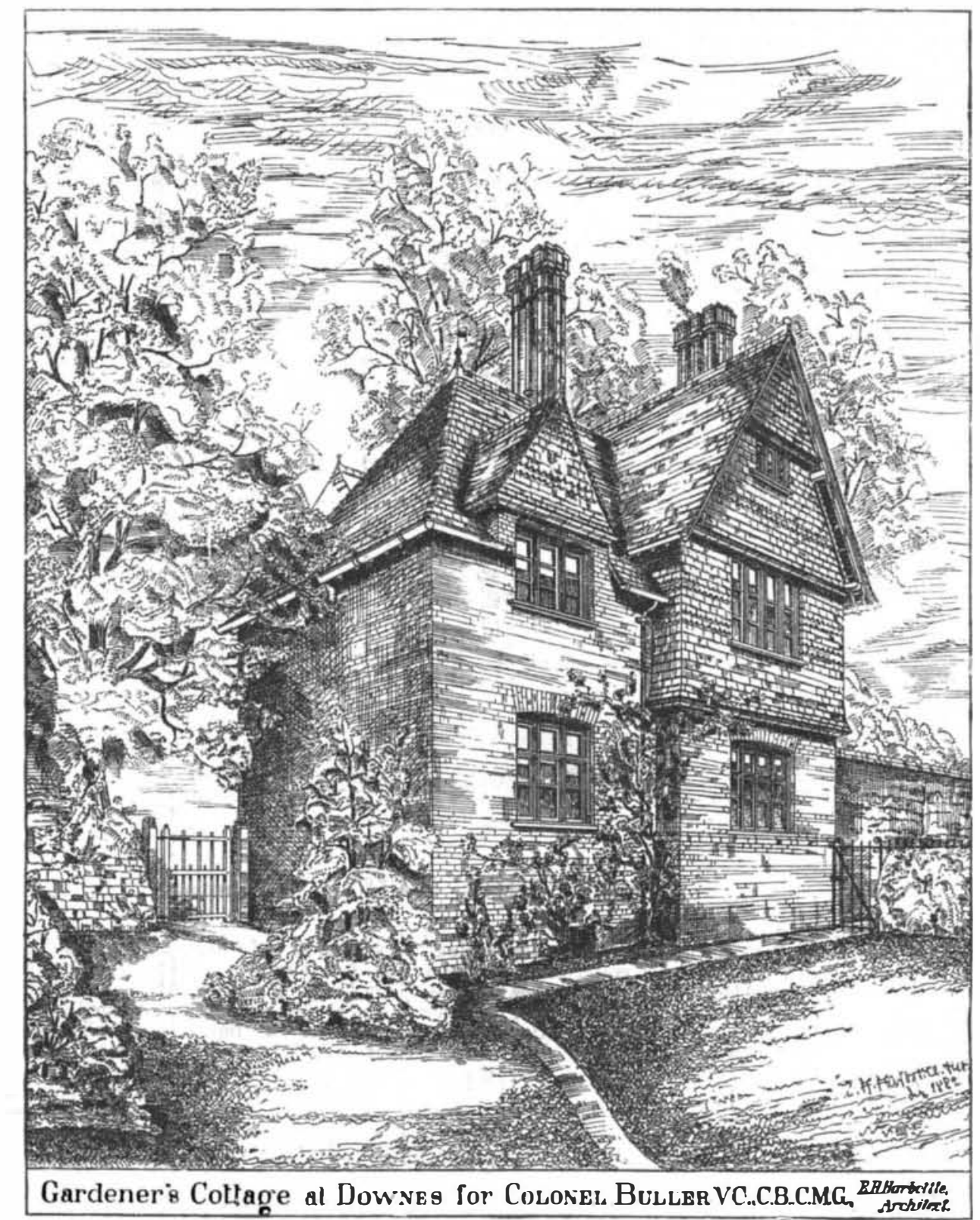

DESIGN FOR A GARDENER'S COTTAGE.

THE illustration shows a gardener's cottage recently V.C., C.B , C.M.G., from the designs of Mr. Harbottle, A.R.I.B.A., of Exeter. It is built of red brick and tile, picturesque which and the outline of the cottage give it a in one of the finest parks in Devonshire.-The Architect.

PAPER MAKING "DOWN EAST."

WRITING trom Gilbertville, a Lewiston journal correspondent says: Gilbertville, a manufacturing community in the Androscoggin, is now a village of over 500 inhabitants, where three years ago there was but a single farmbouse.
If a town had sprung into existence in a far Western State If a town had sprung into existence in a far Western State
with so much celerity, the phenomenon would not be conare not indigenous to the New England of the present era. Gilbertville has probably outstripped all New England villages in the race of the past three years. It is only one of
the signs that old Maine is not dead yet. Gilbert Brothers erected a saw mill here three years ago.
A year later, the Denison Paper Manufacturing Company, A year later, the Denison Paper Manufacturing Company,
of Mechanic Falls, erected a big pulp mill. which, also, the town voted to exempt from taxation for ten years. The mills are valuable companions for each other. The pulp was speedily built by the operatives. Gilbertville now boasts of a post-office, a store, several large boarding houses,
a nice school house, and over 500 inhabitants. The pulp a nice school house, and over 500 inhabitants. The pulp
nill employs seventy men. It runs night and day. It pulp. It consumes monthly 500 cords of wood for fuel, 45 casks of soda ash, valued at $\$ 45$ per cask, nine car-loads of lime, 24,000 pounds to the car. It produces $1,000,000$
pounds of wet fiber, valued at about $\$ 17,000$, monthly. The pounds of wet fiber, valued at about $\$ 17,000$, monthly. The

The larger part of the stock used by the mill consicts of
poplar logs floated down the Androscoggin and its tribufour-foot lengths are piled about the mill: and a little curther up the river are 5,000 cords more. The logs are hauled from the river and sawed into lengths by a donkey engine, which cuts about sixty cords per day, and pulls out fourteen logs
at a time. All tbe spruce slabs made by the saw mill are used with this poplar. The wood is fed to a wheel armed
with many sharp knives. It devours a cord of wood every chips as rapidly as they can be thrust into the maw of the chopper. They are carrried directly from this machine to
the top of the mill by an endless belt with pockets attached.

sure, and is very stoutly made of thick iron plates, bolted / easily wbitened. The line oath is the purgatory of the

ogether.

the same paper says: There are six of thesechanic Falls, Before we go any further, we must see what becomes of three dams over which the Little Androscoggin falls on the these sofit and lop-sided bundles which are going into the and the super-calendering mills. The Eagle and the Star , tain percentage of which is used in nearly all the papers
made now. It gives the paper a greater bodv, although its mills run on bork papers of various grades. The Union mader is not so strong as that made of rags. The pulp comes
till pares pulp stock. The pulp mill does nothing but bleach bleached. The brown fiber is placed in a batt of cold water the rag pulp and prepare for the machines in the other mills; and chlorate of lime. There it quietly rests till a sedimen while the super-calendering mill gives the paper an extra setiles at the bottom of the tank. At an opportune moment

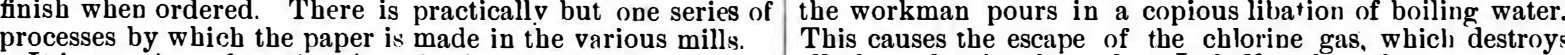
It is a curious fact that America is not ragged enough to all the color in the pulp. In balf an hour it comes out. mills. Nearly all the rags used by the Der its own paper mass of smoking thers as white as anowe by others in various parts of the country as well) are im- floors. The pulp remains in the drainers till it so dry it is ported from the old countries. All the rags first go through bandled with a pitchfork. the "duster." This is a big cylindrical shell of coarse wire We are now ready to look at the beating machines, whic through its center is turned in the opposite direction. Air These are large iron tanks with powerful grinders revolvin currents are forced through it by a power fan. The rags in them. Barrow loads of the brown rags are dumped int about ten feet long and fone end of this shell. which $\mathrm{s}$. $\mathrm{them}$, and clear cold water is pou into fine bits. They kee forces them througb the whole length of the shell, while the mass of rags and water circulating incessantly in the heyare kept buzzing around and subjected to breezes which tanks. Clean water constantly flows in and dirty water as blow thick clouds of dirt and dust out of them. The air of constantly flows out. In the cnurse of six hours the ra are

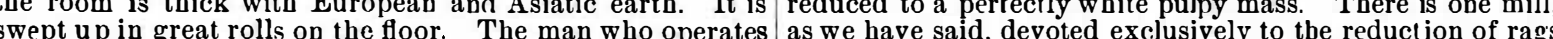
\begin{tabular}{ll} 
the duster should have leather lungs. & to this white pulp. It is dried in drainers such as we saw a \\
\hline
\end{tabular} Overhead is a long room where thirty girls are busily fer moments ago filled with the wood fiber. \begin{tabular}{|l|l|l} 
dusting machine is no more perfect than a human machine & perform a slightly different service. Their function may \\
is evinced by the murky atmosphere of this room, by the & be compared to that of an apothecary's mortar or a cooks
\end{tabular} 